\title{
Estudos de Mídia, Marxismo, Globalização e Sistemas de Comunicação em países em Transição
}

\section{Colin Sparks}

\section{Entrevista concedida a Andrea Medrado*}

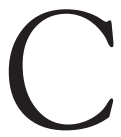

olin Sparks é um dos expoentes da Economia Política da Comunicação. Participou das origens da escola de Westminster, como esta foi denominada por James Curran, que se contrapunha aos estudos culturais. É também um dos fundadores do renomado periódico acadêmico Media Culture $\mathcal{E}$ Society. Depois de mais de 30 anos atuando no Reino Unido, mudou-se para Hong Kong em 2011, onde poderá se aprofundar em sua pesquisa sobre a China. $\mathrm{Na}$ entrevista abaixo, Colin Sparks

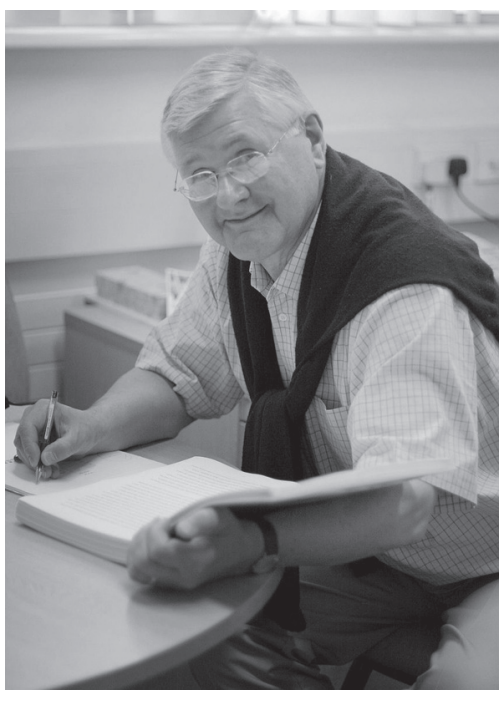

* Pós-doutoranda e professora no Departamento de Estudos de Artes Midiáticas na Royal Holloway, Universidade de Londres. Sua pesquisa atual investiga a produção de programação cross media pelas redes públicas de radiodifusão (BBC e Channel 4) no Reino Unido. Concluiu seu doutorado em Estudos de Mídia pela Universidade de Westminster em Londres em 2010. Sua tese de doutorado é um estudo etnográfico sobre o papel das rádios comunitárias dentro do contexto cotidiano e do ambiente sonoro de uma favela em Salvador. E-mail: ammedrado@hotmail.com 
relembra o longo trajeto dos estudos de mídia e Comunicação, partindo timidamente das margens até desembocar na corrente principal dos meios acadêmico e intelectual. Sempre que surge a oportunidade, faz questão de se autoproclamar um "marxista" e um revolucionário. Um dos críticos das teorias de globalização, ele as situa dentro de um contexto histórico em que, conforme identifica, se abriu uma lacuna para buscar novas teorias que explicassem as "grandes histórias" da segunda metade do Século $\mathrm{XX}$ até os dias atuais. Nos últimos anos, Sparks tem se voltado para o estudo dos sistemas de comunicação de países em transição, como países pós-comunistas e recém-saídos de regimes políticos autoritários. Esta pesquisa acabou por levá-lo a se interessar pela América Latina e pelo Brasil. Entretanto, sua busca é sempre por um foco global: "um cientista social deve estar interessado no que está acontecendo no mundo”. Marxismo, globalização, política (e política brasileira), BRICs, todos estes aspectos fazem parte desta ampla análise do cenário global a que se refere. Entretanto, desde sua mudança para Hong Kong, os grandes desafios que Colin Sparks tem enfrentado não tem sido representados por complexas questões teóricas, mas sim, por simples aspectos da vida cotidiana.

Revista Intercom - $\mathrm{O}$ senhor testemunhou o estabelecimento e crescimento da escola de Westminster (Westminster school) para usar uma expressão de James Curran. Quais foram as origens desta escola e de que maneira ela contribuiu para dar um molde à disciplina de estudos de Mídia no Reino Unido e no mundo? Colin Sparks - Há duas maneiras de se olhar para as origens de escola de Westminster: a primeira diz respeito ao período e a segunda diz respeito aos indivíduos. A escola de Westminster foi fundada e iniciou sua existência no início e até meados dos anos 1970. Como todos sabem, este foi um período de muita agitação social e de radicalização de uma parte significativa da intelligentsia e em especial dos membros mais jovens da intelligentsia, muitos dos quais tinham inclinação para uma ou outra variante do Marxismo. Então, acho que a escola de Westminster deve ser vista dentro deste contexto amplo. Acredito que atualmente muitos dos membros que associamos com a escola de Westminster não 
se identificariam como marxistas confessos, mas o fato é que naquele contexto muitos jovens intelectuais se identificavam como tal. Portanto, talvez este seja o selo inicial de Westminster, como também o foi para muitas outras correntes intelectuais. A área de estudos culturais, por exemplo, também obteve seu formato mais conhecido durante aquele período e foi igualmente influenciada, de uma maneira geral, pelo marxismo. $\mathrm{O}$ que era distintivo sobre a versão da escola de Westminster era que ela se voltava para o que poderíamos chamar de uma versão economicista do marxismo. Mais uma vez, o contraste com os estudos culturais se fazia claro. Os estudos culturais foram fortemente influenciados por uma tradição Althusseriana do marxismo que efetivamente descarregava a ideia de determinação em favor de um foco nas práticas de significação que se derivavam automaticamente da sóciolinguística. A escola de Westminster começou a se desenvolver em grande parte como uma reação a esta tradição: dava destaque à economia, dava destaque à determinação material e portanto, de muitas maneiras, se mostrava distinta com relação aos estudos culturais. Havia uma outra corrente naquele tempo que era muito influente, mas que não deixou uma marca tão grande nos estudos de mídia, que era a tradição de análise psicanalítica, em torno do periódico Screen. Devemos lembrar que naquela época o campo era bastante restrito, todo mundo conhecia todo mundo, então tudo isso ocorreu, em grande parte, no âmbito de uma única geração. Não havia o grau de dispersão que encontramos hoje quando pessoas da área de estudos de cinema mal se comunicam com pessoas que estudam jornalismo. A escola de Westminster originou-se assim.

Eu também creio que, dentro destas circunstâncias, devemos partir do clima geral intelectual em direção ao papel específico de alguns indivíduos. Não há dúvida que a pessoa mais influente dentro da Escola de Westminster foi Nicholas Garnham. Paddy Scannell e um outro pesquisador chamado David Cardiff já estavam trabalhando em Westminster, mas naquele período ainda não havia uma identidade ou formato definidos para a escola. Garnham recrutou um grande número de pessoas. Ele recrutou James Curran, Richard Collins e me recrutou também. Então, Garnham conferiu um caráter distinto nas áreas-chave em que tinha interesse através 
do seu recrutamento de pessoas. Retrospectivamente, nós éramos identificados por trabalhar mais na área de história, como Paddy Scannell e James Curran, ou nas áreas econômica ou economicista como Richard Collins, Vincent Porter e eu. Então, a escola que emergiu foi tanto histórica quanto materialista e acho que a maioria dos praticantes se intitulam materialistas históricos. $\mathrm{O}$ único que afirmaria nunca ter sido um marxista e o afirmaria com razão seria James Curran, mesmo tendo sido simpático a vários aspectos da crítica marxista à cultura. Estas são as origens - vieram de um momento de radicalização e faziam parte de um entusiasmado engajamento com o marxismo. Talvez você não conheça o poeta inglês William Wordsworth, que esteve na França em 1789, quando era jovem e, assim como muitos membros da escola de Westminster, mais tarde em sua vida se tornou uma reacionário. Na sua velhice ele olhou para trás, para sua juventude, e disse: "benção foi nessa madrugada estar vivo, mas ser jovem era o paraíso" ("bliss was in that dawn to be alive, but to be young was very heaven"). Eu acho que era este o sentimento que cercava a vida intelectual, em geral, e o estudo de mídia e comunicação, em particular, durante aquele período. Nossa trajetória específica foi muito mais excêntrica. A tendência dominante no marxismo era, sem dúvida, Althusseriana, seja na versão proposta pelos Estudos Culturais ou na versão psicanalítica do periódico Screen. Pessoas como Stuart Hall, David Morley, John Ellis, Ros Coward eram muito mais representativas da corrente intelectual geral daquele período do que alguém como Nick Garnham ou Richard Collins ou eu.

Revista Intercom - Quais avanços obtivemos no estabelecimento dos estudos de mídia e comunicação como um campo legítimo de investigação?

Colin Sparks: Os estudos de jornalismo e comunicação têm um alicerce significativo nos Estados Unidos e também algumas dimensões europeias. Porém, o fato é que na Grã Bretanha, onde a escola de Westminster se situava, os estudos de mídia eram institucionalmente muito marginais. Os estudos de cinema estavam muito melhor representados, em várias derivações, em departamentos de inglês, mas os estudos de mídia praticamente não existiam em 
lugar algum e jornalismo mal era ensinado a nível universitário. Westminster era a Politécnica do Centro de Londres (Polytechnic of Central London). Posso usar a analogia da California State University, em contraste com a University of California. A politécnica era em sua maior parte uma instituição de ensino, com uma forte orientação vocacional e foi lá que o primeiro curso de bacharelado em estudos de mídia foi estabelecido. Garnham havia contratado todas aquelas pessoas para poder montar a equipe de professores necessária para o estabelecimento de um curso de bacharelado. Você pode pedir a ele para ver os primeiros planos de disciplina do curso, escritos em 1974. Eu sei que ele ainda os tem porque ele os roubou de mim. Seria válido examiná-los, seria muito interessante ver o que os estudos de mídia significavam em 1974. O campo situava-se mesmo nas margens e não existia em porcentagem significativa em nenhuma das universidades bem estabelecidas. Havia centros de pesquisa em Birmingham, em Leicester, que eram mais voltados para a sociologia clássica ou talvez oferecessem outra versão de economia política e, mais tarde, em Glasgow. Todas essas eram universidades estabelecidas e de prestígio que promoveram esforços significativos de pesquisa. Porém, o ensino de estudos de mídia foi em grande parte construído nas politécnicas, nas State Universities e não foi até a década de 1980 que houve uma expansão significativa do número de instituições que ensinavam estudos de mídia. Esta expansão foi guiada e, de fato, ainda tem sido guiada no mundo todo por uma demanda muito forte dos estudantes que desejam estudar jornalismo, produção de $\mathrm{TV}$, rádio e assim por diante. $\mathrm{O}$ que a universidade tem feito ao estabelecer cursos de estudos de mídia é basicamente responder às forças do mercado. $\mathrm{O}$ que tem ocorrido ao longo do tempo é que o setor tem se legitimado e transferido paras instituições mais prestigiadas. Hoje você vai ver que a London School of Economics, por exemplo, ensina estudos de mídia e comunicação. Oxford e Cambridge também o fazem um pouco, eventualmente os pináculos do ensino superior britânico começaram a fazê-lo. Este é um sinal da maturidade da disciplina, um sinal de sua crescente força institucional e de sua legitimidade. Um dos meus colegas acaba de completar um doutorado em Cambridge... as pessoas 
pensam: "nossa, alguém que está ensinando estudos de mídia e que tem um doutorado em Cambridge”. Então, aí está, veja só, a disciplina é agora legítima. Quero dizer, estudos de mídia ainda não são considerados tão centrais para as humanidades e ciências sociais quanto, por exemplo, economia ou literatura, mas vem, no entanto, gradualmente se transformando em instituições bem estabelecidas dentro de um conjunto de universidades que vai desde as que têm menos prestígio até as mais prestigiadas. Tem sido uma longa marcha, iniciada a partir das margens, mas hoje estudos de mídia são mais ou menos bem aceitos dentro do ambiente acadêmico.

Revista Intercom - E como anda sua pesquisa nas áreas de mídia e transformação social, mídia alternativa e mídia para o desenvolvimento? O senhor aborda bastante estes assuntos em seu livro Development Communication and the Mass Media (Comunicação para o Desenvolvimento e Mídia de Massa, sem tradução para o português). E, como sabemos, o senhor também é um marxista confesso... Colin Sparks - Eu ainda sou um marxista auto proclamado, sim, mas sei que ninguém vai concordar comigo.

Revista Intercom - De que forma essa preocupação com os meios de comunicação para a transformação social, para melhorar as condições daqueles que são menos favorecidos, faz parte do seu trabalho? Colin Sparks - Deixe-me voltar a dizer que houve um momento em que num corredor do edifício da universidade de Westminster, no centro de Londres, James Curran era o editor da revista teórica do Partido Trabalhista. Eu era editor da revista mensal do Partido Socialista dos Trabalhadores e havia uma mulher chamada Irene Brennan que era integrante do conselho editorial do jornal do Partido Comunista. Éramos todos do mesmo departamento, éramos conhecidos como, digamos assim, os "chapeuzinhos vermelhos". Certamente nos enxergávamos como sendo parte de um movimento para mudar o mundo e, em maior ou menor grau, tínhamos um engajamento político direto. Garnham, por exemplo, tinha envolvimento em vários movimentos sociais e também nos sindicatos. Ele também se envolvia na tentativa de democratizar programas de TV 
e de democratizar as estruturas da televisão para que ela se tornasse mais sensível aos interesses populares e assim por diante. James Curran tentava modificar o Partido Trabalhista e, de maneira mais geral, a opinião pública com relação às estruturas da imprensa. Tentava conscientizar a opinião pública a respeito do domínio do discurso público por um pequeno número de indivíduos e de organizações. Eu, pessoalmente, tinha e ainda tenho uma maior preocupação com questões sociais do que com questões de organização técnica.

Uma das características distintivas de Westminster e essa característica, eu acho, ainda se faz presente no trabalho da maioria das pessoas em Westminster e no trabalho de muitas das pessoas que são influenciadas por Westminster, é que eles não são centrados na mídia em si (da expressão em inglês media-centric). Eles não pensam que a questão fundamental seja a natureza dos meios de comunicação de massa ou no que estes meios de comunicação de massa possam fazer. Eles pensam na mídia como existindo em torno dos aspectos sociais (social-centric). Os meios de comunicação são: a) um produto de sociedade, b) um sintoma da sociedade, c) um local privilegiado a partir do qual os problemas da sociedade podem ser explorados e examinados. Nos anos 1970, para muitas pessoas, realmente parecia haver uma oportunidade real de mudanças sociais significativas e, portanto, uma oportunidade de mudança também da mídia, mesmo na Grã Bretanha. Agora eu percebo que, hoje, parece que nada muda na Grã-Bretanha, exceto para pior - não há chances de democratização da mídia, há ainda o punho de ferro dos oligopólios... a ideia de que poderia haver uma transformação destas instituições em instituições democráticas que responderiam às necessidades das massas agora nos parece irrealista. Mas isso parecia uma possibilidade real na década de 1970. Ela desapareceu lentamente no decorrer da década de 1980 e este foi também o caso de muitos indivíduos. Houve um recuo lento do radicalismo. James Curran manteve suas posições radicais. Ele era um social- democrata na década de 1970, ele era um social-democrata na década de 1980, ele era um social-democrata em 2000 e ele é um social-democrata hoje. Ele não se afastou do seu desejo de reformar os meios de comunicação. E eu acho que fui um revolucionário em 1970 e sou um revolucionário hoje e ainda não desisti do meu 
desejo de transformar a mídia politicamente. O que eu acho que é muito mais claro hoje é a maneira com que este projeto tornou-se um projeto global. Originalmente, o horizonte da escola de Westminster era apenas o Reino Unido. Não que nós não estivéssemos interessados no que acontecia em outros lugares do mundo, mas nossos horizontes reais eram muito restritos ao ambiente nacional. Eu acho que se você olhar para quem trabalha na universidade hoje, você verá que a transformação foi ampla. Para começar, o quadro de funcionários não é mais todo composto por pessoas do sexo masculino como era antes... na verdade, havia apenas uma pessoa do sexo feminino naquele tempo: Helen Bear. Hoje, acho que metade do quadro é composto por mulheres. O quadro tampouco é todo formado por brancos. Muitos já não mais carregam passaportes do Reino Unido. Muitos sequer se concentram no que ocorre no chamado "mundo desenvolvido". Então houve muitas mudanças, temos nos tornado internamente muito mais internacionalizados e estamos muito mais engajados com questões de mídia global. Até que ponto isso significa um foco em questões de transformação social naturalmente varia. As discussões sobre mídia global tendem a ser focadas, num nível abstrato, nas corporações da mídia global e na circulação de formatos. Mas acredito que certamente tem existido um maior envolvimento com questões mais tradicionais de mídia para a transformação social. Por exemplo, Naomi Sakr (também professora e pesquisadora em Westminster) tomou uma iniciativa logo após a deposição de Mubarak para ajudar a região a estruturar sua radiofusão de uma maneira mais democrática. Esta preocupação tem se tornado um projeto global: uma preocupação com o desenvolvimento, ensino e pesquisa em torno de temas colaterais da comunicação para o desenvolvimento, particularmente em torno das diferentes noções de participação. Em termos do que realizamos na área de educação, basta prestar atenção em nosso corpo de estudantes de pós-graduação, por exemplo: ele é formado pelos filhos e filhas dos novos ricos chineses... Eu acho que devemos fazer um esforço sério para tentar mudar isso, como Winston Mano (também professor na Universidade de Westminster), por exemplo, tem feito para tornar a pós-graduação acessível para estudantes de países em desenvolvimento. Esta será uma maneira de restabelecer o diálogo 
com muitas das questões centrais sobre o potencial de utilização dos meios de comunicação para melhorar a vida das pessoas.

Revista Intercom - E a América Latina seria um pouco como o elo perdido nas instituições de pesquisa do Reino Unido de maneira geral?

Colin Sparks - Bem, se você olhar para a escola de Westminster retrospectivamente, por exemplo, verá que em suas origens ela se parece com um grande plano, mas na verdade não era um grande plano, mas apenas uma resposta às necessidades, às demandas e aos interesses do quadro de pesquisadores e de estudantes de pós graduação. $\mathrm{O}$ que aconteceu foi que nenhum dos pesquisadores se comprometeu com o desenvolvimento de trabalhos de pesquisa na América Latina, mas a América Latina não é a única lacuna a ser preenchida. A América do Norte também está ausente e é lá que existe o sistema de mídia que exerce a maior influência no mundo. Há muitas iniciativas interessantes ocorrendo que talvez não estejam fazendo tremer as bases da Fox ou do New York Times, mas, pelo menos, têm contribuído para globalizar o descontentamento com a dominação corporativa dos meios de comunicação americanos. Então, acho que podemos com certeza aprender algumas lições enriquecedoras da América Latina, mas também da América do Norte.

Além disso, a atual realidade financeira do Reino Unidos faz com que nós estejamos num momento de encolhimento ao invés de um momento de expansão. Uma maneira de preencher esta lacuna seria construir laços mais fortes com universidades latino-americanas. Enfim, espero que sejamos capazes de compartilhar laços mais fortes com universidades brasileiras. Há sempre um problema na América Latina: muitos pesquisadores são tão mal pagos que precisam realizar outros trabalhos, às vezes em diversas universidades e portanto suas oportunidades de pesquisa são muito limitadas. Um ex-aluno de doutorado, que é argentino e trabalha em Buenos Aires me fala que tem que ensinar o tempo todo para poder pagar o aluguel. Eu acho que isso também deve acontecer em alguns lugares no Brasil. É óbvio que nós sempre nos queixamos sobre a difícil situação em que nossas instituições se encontram, mas há muitas pessoas em situações bem piores. 
Revista Intercom - O senhor desmistifica a ideia da globalização como uma nova época na história da humanidade. Para citar o que o senhor escreveu: "a globalização pode ser melhor entendida como um aspecto do desenvolvimento capitalista do que como o produto de um novo fenômeno social distinto chamado de globalização". Poderia elaborar um pouco mais sobre este seu conceito de globalização?

Colin Sparks - Em primeiro lugar, eu não pretendo negar a realidade. Eu estou aqui em Hong Kong, você está em Londres. Você é brasileira, nós estamos discutindo através do Skype, um link internacional de comunicação. Claramente há algo diferente. Minha mãe nunca saiu de seu país de origem. Minha filha saiu do país pela primeira vez quando tinha 2 meses de idade. Obviamente há um grau muito maior de mobilidade internacional entre as pessoas, entre as ideias, entre o capital e todos os tipos de coisas. A questão é: como teorizar tudo isso? Houve um momento histórico em que todos nós tivemos uma consciência política muito forte em oposição à Guerra do Vietnã, por exemplo, porque ela manifestava o imperialismo de forma muito transparente: um país pequeno e pobre sendo invadido por um país grande e rico. Era o imperialismo se manifestando de maneira muito clara e portanto nós precisávamos teorizá-lo. Quando aquele momento passou, as pessoas passaram a buscar outras explicações para o mundo. Além disso, à medida em que o marxismo associava-se fortemente aos sistemas moribundos da União Soviética e, de uma forma diferente, ao sistema da China, passou a haver mais espaço para a procura de teorias alternativas. A esquerda, por exemplo, apoiou-se num conjunto de iniciativas destinadas a equilibrar o poder comunicativo do mundo, para que o mundo desenvolvido pesasse menos nesta balança e para que surgisse uma visão mais representativa da população mundial como um todo. Mas o fato é que, ao fazer isso, e certamente a UNESCO alinhou-se com um grupo terrível de pessoas que, de maneira geral, se aproveitaram da ideia de liberdade de expressão para oprimirem a população. Então havia mesmo uma brecha para que surgissem outras teorias, ainda mais depois de 1989, quando parecia que o marxismo 
tinha caído e sido enterrado junto com o comunismo soviético, em 1991. E estas teorias pareciam afirmar que o capitalismo havia superado suas contradições clássicas com o marxismo, elaboravam formulações clássicas da não redutibilidade da cultura diante do desenvolvimento econômico, todas estas eram tentativas de teorizar o mundo. O livro de Fukuyama, por exemplo, "O Fim da História" foi muito influente. As pessoas realmente estavam convencidas de que o capitalismo representava o ponto alto e inevitável do desenvolvimento humano e que o conflito entre capitalismo e comunismo já estava desatualizado. Eu acho que as teorias de globalização se encaixavam bem dentro deste contexto, mas quando adotamos este programa de pesquisa, começamos a obter uma imagem um tanto distorcida da realidade. Gostaria de dar dois exemplos: um deles é a noção de que o Estado-Nação não seja mais um ator importante no cenário global. Eu estive lendo recentemente um livro escrito por Michael Keane, Anthony Fung e Albert Moran chamado "New Television, Globalization and the East Asian Cultural Imagination"

(Nova Televisão, Globalização e Imaginação Cultural da Ásia Oriental, sem tradução para o português). Neste livro a ideia de que o papel do Estado não seja mais tão significativo está bastante presente, mas não creio que seja este o caso. Recentemente, por exemplo, vimos os Estados da Grã Bretanha e da França exercerem seus poderes na Líbia de forma sórdida. O segundo exemplo se refere ao assunto da migração internacional. Claro que a migração internacional tem significância, mas o maior crescimento em migração na última metade do século foi o do interior e da zona rural em direção à cidade. $O$ Brasil é um exemplo clássico, a China também. A forma mais dramática de crescimento e movimento populacional tem sido do campo para a cidade. Esta tem sido a principal forma de migração dos últimos 20, 30 anos.

Revista Intercom - O senhor já chamou atenção para o quanto o mundo ocidental "desenvolvido" se esquece de que ainda há muitos lugares no mundo sem acesso à internet. Diante da recente primavera árabe, o senhor acha que tenhamos motivos para ser- 
mos otimistas com relação ao potencial democratizante das redes sociais, por exemplo?

Colin Sparks - Qual é o nível de conectividade no Egito? Que porcentagem da população está on-line? Desconfio que o papel das redes sociais dentro da primavera árabe tenha sido mais relevante para os alunos de pós-graduação nos Estados Unidos... Tivemos uma sessão em uma conferência árabe e muitas pessoas disseram que sim, houve uma grande atividade nas redes sociais, mas, na verdade, se formos realistas, a Al Jazeera foi mais importante. Com as redes sociais estamos falando de um número relativamente pequeno de pessoas. Portanto, a Al Jazeera foi a principal condutora desta mudança. As redes sociais foram importantes, claro, principalmente dentro do contexto da diáspora árabe. Mas creio que tenham sido mais importantes para as pessoas do Ocidente que passaram a simpatizar com as massas egípcias, mas, para ser sincero, eu não as vejo como sendo as principais forças organizadoras. O boca-a-boca e a televisão provavelmente representaram os principais fatores de transformação. Eu não sei exatamente qual é a penetração da Internet na Síria, mas duvido que tenha sido um fator-chave.

Revista Intercom - Como se deu o interesse do senhor por analisar os sistemas de comunicação de países em transição, como os dos países pós-comunistas ou países recém saídos de ditaduras militares e regimes autoritários?

Colin Sparks - Bem, é um pouco chato falar de países como a Grã-Bretanha e os Estados Unidos, onde nada acontece. Sério, acho que se você olhar para a Grã-Bretanha, os Estados Unidos e a maioria dos países europeus, você encontrará sistemas de comunicação que possuem variações de tempo, mas mantêm fortes continuidades e um forte grau de visibilidade. Portanto, uma análise destes sistemas não necessariamente gera perguntas interessantes e originais. Por exemplo, o serviço público de radiodifusão tem sido debatido incessantemente na Europa durante os últimos 30 anos. Embora os debates tenham caminhado para a frente, eles se movem lentamente. Eu estou mais interessado em coisas que parecem estar se modificando, se transformando. Essas transfor- 
mações nos levam a investigar questões teóricas importantes e interessantes. Na década de 1980 o fim do comunismo europeu foi a grande história. Na década de 2000 a ascensão da China é a grande história. Um cientista social deve estar interessado no que está acontecendo no mundo. Quando essas histórias nos absorvem, passam a desenvolver uma dinâmica própria e é a partir disso que surge a literatura acadêmica. Enfim, estas tornam-se tentativas de sistematizar uma posição teórica com relação ao que começa como uma série de eventos interessantes. Foi assim que eu comecei a pesquisar a África do Sul, a América Latina e mais recentemente o mundo árabe.

Revista Intercom - Com relação ao Brasil, o senhor argumenta que, embora o país tenha passado por um verdadeiro processo de redemocratização, as velhas elites ainda conservam, em grande parte, o poder. Com o recente desenvolvimento econômico e social do Brasil, o senhor crê que tenhamos motivos para sermos mais otimistas?

Colin Sparks - Bem, minha tendência é dar ênfase à ideia de continuidade. Há um espectro de continuidade. A China é um bom exemplo de continuidade substancial: o partido comunista ainda está no poder, os filhos e filhas dos burocratas comunistas são os novos capitalistas, o partido ainda controla todos os meios de comunicação e assim por diante. Portanto, este é um exemplo de continuidade forte. No outro extremo, temos a África do Sul, onde houve uma renovação muito significativa das elites. Há 30 anos as elites políticas eram inteiramente formadas por brancos. Hoje, são inteiramente formadas por negros. Portanto, claramente, algo mudou. Na América Latina, temos um caso que se situa entre estes dois extremos. Há algum grau de renovação no Brasil. É possível ver exemplos da elite política sendo renovada. No entanto, uma das coisas que frequentemente acontecem, é este o caso da África do Sul, é que as novas seções das elites que surgiram rapidamente se adaptam e incorporam práticas das velhas elites. Na África do Sul surge uma grande tensão no momento em que os principais figurões do CNA (Congresso Nacional Africano) se tornam milionários. Eu acho que no caso do Partido dos Trabalhadores e do governo Lula no Brasil o processo não tenha 
sido tão dramático. Pelo menos eu nunca ouvi acusações de que ele pessoalmente esteja tão corrompido, não da maneira em que toda uma gama de políticos Sul-Africanos está voltada apenas para seus ganhos pessoais. No entanto, a vitória e consolidação do PT no Brasil vieram acompanhadas de uma acomodação com o capital brasileiro, da mesma forma que o Partido Trabalhista se aconchegou com o capital britânico, da mesma forma que grande parte do partido comunista Italiano chegou a um ponto de acomodação com o capital italiano. É evidente que Lula representou uma reconfiguração de poder dentro da elite e do sistema político brasileiros. Mas houve uma mudança significativa com relação à situação social das famílias mais pobres. Acho que tem havido um progresso real. Entretanto também é verdade que sempre, nestes casos, haja um grau de renegociação entre as velhas e novas elites. $\mathrm{Na}$ África do Sul o que ocorreu foi que uma camada significativa do CNA se tornou integrante da classe dominante. Já no Brasil foi realizada uma série de concessões aos mais pobres dentro da sociedade. Poderíamos dizer que é tudo uma ilusão, mas parece, pelo menos para os observadores de fora, que alguns ganhos reais tenham sido alcançados no Brasil.

Revista Intercom - E qual a opinião do senhor com relação ao papel dos BRICs dentro de uma possível reconfiguração de poder no mundo?

Colin Sparks - Claramente a época da dominação Atlântica do mundo está passando. Sendo o marxista que sou, acredito que o poder siga a economia, como está acontecendo com a China, Brasil, e em menor medida na Rússia, talvez também na África do Sul. A relação do Brasil com a China tem sido em grande parte uma relação de exportação de matérias-primas, embora o crescimento da economia brasileira tenha sido real. A economia chinesa, claro, é uma economia voltada para a exportação. Há um crescimento real lá. É evidente que os padrões do comércio mundial e do poder econômico estão mudando. Mas em termos de mudanças políticas, ainda não é o caso. Os Estados Unidos ainda são predominantemente uma força mundial de dominação militar. A Marinha dos Estados Unidos possui a maior frota do mundo com 
onze porta-aviões enquanto que ainda deve demorar uma década ou mais para que a China seja autorizada a usar porta-aviões. Há uma incompatibilidade entre as realidades econômicas e as realidades políticas e militares do mundo. Em que cidade fica a sede do Banco Mundial? Em que cidade está situada a sede das Nações Unidas? O contorno político do mundo ainda reflete um domínio forte dos Estados Unidos. Os Estados Unidos são a maior potência militar. Historicamente, os exemplos que temos de descompasso de poder político e militar com relação ao poder econômico não são animadores. No futuro o que vejo é a contínua ascensão econômica desses países acompanhada por um aumento em seu poder político, militar e também simbólico. A China passará de país importador a exportador de programas de TV. Na verdade, neste caso, o Brasil já realizou esta transição.

Revista Intercom - Em 2011 tivemos o escândalo dos grampos do tabloide News of the World, que fazia parte do conglomerado de comunicações de Rupert Murdoch. Sendo um estudioso da economia política da comunicação, o senhor comemorou o encerramento das atividades do tabloide?

Colin Sparks - Claro! O que penso sobre isso? Acho que o poder de Murdoch já não está mais centrado em seus jornais. Os jornais eram importantes geradores de dinheiro há 20 anos, 30 anos. Hoje a Sky é sua maior fonte de riqueza. Até o presente momento, o domínio da Sky (no Reino Unido) possui três aspectos centrais: 1) o monopólio da cobertura esportiva; 2) uma série de acordos com estúdios de Hollywood; 3) o controle sobre os aparelhos decodificadores para TV digital. Até agora eu não vejo nenhum sinal de que qualquer um destes aspectos esteja sendo contestado pelas entidades reguladoras. Portanto, nenhuma das bases de negócios de Murdoch mostra sinais de estar sendo ameaçada.

Revista Intercom - Depois de construir sua carreira na Universidade de Westminster em Londres o senhor acaba de se mudar para a Hong Kong onda atuará na Hong Kong Baptist University. Como foi essa mudança? Quais são seus planos para o futuro?

Colin Sparks - Eu tenho interesse na China há muitos anos e 
vir para Hong Kong vai possibilitar minha realização de mais pesquisas sobre o país. Também terei a oportunidade de aprender chinês. Se não o fizer, serei apenas mais um observador externo. É uma perspectiva um tanto assustadora, não com relação a minha carreira em si, mas com relação às tantas coisas básicas sobre as quais ainda não sei. Por exemplo, eu ainda não sei onde cortar meu cabelo. Existem muitas coisas básicas da vida cotidiana que estou tendo que aprender muito rapidamente. As aulas começam esta semana e estou prestes a descobrir se os estudantes chineses na China são diferentes dos estudantes chineses na Grã-Bretanha. Os estudantes chineses na Grã-Bretanha são esforçados, trabalham duro, são muito educados. Já os estudantes chineses na China ... quem sabe como eles vão ser? Hong Kong é o local ideal para mim porque está muito perto da China. Obviamente, é parte da China, mas também é um local muito mais aberto. O grau de liberdade que terei aqui também contribuiu para a minha decisão. Em muitos aspectos temos aqui um ambiente universitário ocidental. Enfim, tenho certeza que será um ambiente ideal para meu trabalho, uma vez que eu consiga vencer os pequenos desafios da vida cotidiana. 